\title{
Effect of Consumption of Whole-Wheat Breads on FBS, HbA1C, and Blood Lipids in Patients with Type 2 Diabetes
}

\author{
Javad Nazari ${ }^{1}$, Nasrin Yadegari ${ }^{2}$, Sousan Khodam ${ }^{2}$, Amir Almasi-Hashian ${ }^{3}$, and Saeed Amini ${ }^{4}$ \\ ${ }^{1}$ Department of Pediatrics, School of Medicine, ${ }^{2}$ Department of Nutrition, Deputy of Health, and \\ ${ }^{3}$ Department of Epidemiology, School of Health, Arak University of Medical Sciences, Arak, Iran \\ ${ }^{4}$ Department of Health Services Management, Khomein University of Medical Sciences, Khomein, Iran
}

\begin{abstract}
Whole-wheat can have positive effect on blood parameters, such as blood sugar and fat profiles, in patients with diabetic. The aim of this study was to assess the effect of whole-wheat breads on hemoglobin A1c (HbA1c) and blood lipids in patients with type 2 diabetes (T2D). The study population included men and women with T2D aged 30 years old and over in Arak, Iran. Using random sampling method, 60 patients with T2D were selected and randomly divided into control and intervention groups. After taking blood samples from the patients, the intervention group was administered $180 \mathrm{~g}$ of wholegrain wheat for 12 weeks. The participants were asked not to change their diets and amounts of physical activity during the study period. After 12 weeks, blood samples were taken and insulin resistance indexes, blood glucose levels, and lipid profiles were examined. The results indicated that consumption of whole-wheat bread for 12 weeks can significantly reduce body weight, and $\mathrm{HbAlc}$, triglyceride, total cholesterol, and low density lipoprotein cholesterol (LDL-c) levels, and increase high density lipoprotein cholesterol (HDL-c) levels $(P<0.05)$. However, in the control group, changes in body weight, body mass index, HbAlc, total cholesterol, HDL-c, and LDL-c levels did not significantly differ before and after the intervention period $(P>0.05)$. As consumption of whole-wheat bread has positive effects on control of various physical and biochemical indictors in patients with diabetes, its consumption should be included in educational programs at health centers across the country.
\end{abstract}

Keywords: diabetes, dietary fiber, insulin resistance, lipid, whole grains

\section{INTRODUCTION}

Diabetes is one of the most common glandular diseases in the world and is responsible for about four million deaths per year (Shaw et al., 2010). Diabetes is not just a disease but includes a series of metabolic disorders caused by impaired secretion and/or function of insulin (American Diabetes Association, 2009). Diabetes is a growing and important concern in healthcare systems worldwide (Whiting et al., 2011; Guariguata, 2012). The World Health Organization has declared diabetes a latent epidemic due to its increasing trend worldwide (Shaw et al., 2010; Whiting et al., 2011; Guariguata, 2012). The latest statistics released by the International Diabetes Federation show that 112.8 million people worldwide aged 65 99 years have diabetes. If the current trend continues, by 2045, 253.4 million people aged $>65$ years will have diabetes worldwide (WHO/IDF, 2006).
The Global Burden of Disease Study 2019 for Iran indicates that $20.1 \%$ of deaths and $11.5 \%$ of disability-adjusted life-years due to non-communicable diseases result from high fasting blood glucose levels (or diabetes) (Global Burden of Disease Study 2019, 2020). Diabetes mortality rates are increasing in Iran, with the standardized mortality rate for diabetes having increased from 8.7 years in 2000 to 11.3 years in 2015 (Veisani et al., 2018). In addition, diabetes has high economic costs for the country, with the cost of treatment for each effected person in Iran in 2009 estimated at 843 USD (Javanbakht et al., 2011). Epidemiological studies have indicated that postprandial blood sugar levels have a higher association with metabolic diseases and diabetes than fasting blood glucose levels (Beisswenger et al., 2004). Considering the importance of regulating blood sugar in preventing diabetic complications, important factors for controlling blood sugar levels include modifying lifestyle and proper nutri- 
tion, especially limiting intake of carbohydrates (Roberts and Liu, 2009) and consuming inaccessible carbohydrates (Livesey et al., 2008). The evidence indicates that both the amount of carbohydrates consumed, but their quality is effective in impacting hyperglycemia after eating (Jenkins et al., 2010). This evidence has evoked dietary associations to recommend that patients with diabetes should consume diets based their effects on the glycemic indexes (Gray and Threlkeld, 2015). Glycemic indexes have been identified in the last two decades (Jenkins et al., 2008b), and different foods have since been studied for their physiological effects instead of chemical compositions (Shishehbor et al., 2013). To date, several studies have been performed to evaluate the clinical effects of foods containing different glycemic indexes in healthy individuals and people with diabetics. Results have shown that diets with low glycemic indexes can reduce the rate of postprandial hyperglycemia in people with type 2 diabetes (T2D) (Jenkins et al., 2008b; Esposito et al., 2010) and prevent metabolic disease by regulating blood sugar levels. Meanwhile, the glycemic responses of foods containing carbohydrate varies between different foods (Jenkins et al., 2008a; Livesey et al., 2008).

Bread is an important component of the Iranian diet, with over $40 \%$ of Iranians' energy and protein consumption coming from bread. Therefore, the nutritional quality of bread can affect public health (Webster and Wood, 1986). Separation of bran from wheat decreases the fiber, vitamin, and mineral content of flour, which can lead to difficulties in blood sugar control in diabetics (Ma and Harwalkar, 1984). The previous studies have shown that cereal fibers have positive effects on glycemic control in people with diabetes and glucose tolerance in people without diabetes (Brodribb and Humphreys, 1976; Bosello et al., 1980). However, these studies are out of date and there is a need for new case-controlled studies to examine the relationship between breads with and without bran and control of diabetes in a real world.

Considering the increasing trend of diabetes in Iran and worldwide, the positive effects of bran on blood parameters and the lack of coherent studies in this field, this study was conducted to investigate the effect of wholegrain wheat bread consumption on fasting blood sugar (FBS), hemoglobin Alc (HbAlc), and blood lipids in people with diabetes.

\section{MATERIAL AND METHODS}

\section{Ethics and safety management}

The experimental protocol was approved by the Ethics Committee of Arak University of Medical Sciences, Arak, Iran (Approval ID: IR.ARAKMU.REC.1397.202) and conformed to the ethical principles set forth in the Declara- tion of Helsinki. Voluntary written informed consent was obtained from all participants.

\section{Study and sampling population}

The population included patients with T2D referred to the Diabetes Center in Arak, Iran. The following formula was used to calculate the required sample size:

$$
\mathrm{n}=\frac{2 \times\left(\mathrm{Z}_{\alpha / 2}+\mathrm{Z}_{\beta}\right)^{2} \times \delta^{2}}{\mathrm{~d}^{2}}
$$

In this formula, a significance level of $5 \%$, study power of $80 \%$ and standard deviation of blood glucose equal to 40 were considered. Furthermore, on the basis of clinical specialists, $\mathrm{d}$ was considered to be 30 .

Finally, the required sample size, considering the probability of losing individuals during the study, was estimated at 30 people in each study group (a total of 60 people).

\section{Inclusion and exclusion criteria}

Participants included in this study had T2D and Iranian citizenship. Participants must had been referred to the Diabetes Clinic in Arak city, be a resident of Arak, Iran, be at least 30 years of age, have fasting blood sugar levels $>140 \mathrm{mg} / \mathrm{dL}$, be willing to participate in the study. Participants were excluded if they were pregnant, unable to attend the study due to medical conditions, were subjecting to special diets or exercise programs, or did not want to eat wholegrain wheat bread.

\section{Method of administration}

After participants were informed about the goals of the project and provided written consent, demographic characteristics were recorded. At the beginning of the study, $5 \mathrm{~mL}$ blood sample was extracted from participants after fasting for 12 14 fasting. In addition, participants were weighed by sulphur oxides emission control areas scales (accuracy of $0.1 \mathrm{~kg}$ ) when wearing minimal clothing and without shoes, and their heights were measured using a portable UNICEF height meter. The participants were randomly assigned to either the intervention or control group. The participants in the intervention group were given $180 \mathrm{~g}$ of wholegrain bread (named Sangak in Iran) daily for 2 months. All participants were advised to include bread as part of their daily three meals and to not change their usual diet and levels of physical activity during the study period. After two months, the participants' weights were re-measured and further blood samples were taken. All tests were performed in the diagnostic laboratory of Arak health center. The tests of HbA1c, FBS, total cholesterol, triglyceride, high density lipoprotein cholesterol (HDL-c), and low density lipoprotein cholesterol (LDL-c) were performed using immunoassay, glucose ox- 
idase, cholesterol phosphate oxidase/peroxidase, and direct methods, respectively.

\section{Statistical analysis}

Data were analyzed using STATA software (StataCorp LLC, College Station, TX, USA) version 13 using $t$-tests, chi-square tests, and regression tests.

\section{RESULTS}

Thirty participants were included in the intervention group and 30 participants were included in the control group. Baseline characteristics of the participants are shown at Table 1. Overall, 47 of the participants were women and 13 were men. The mean ages of participants in the intervention and control groups were $55.33 \pm 9.64$ years and $52.23 \pm 8.79$ years, respectively, and mean BMIs were $29.95 \pm 3.48$ and $28.26 \pm 3.65$, respectively.

Two types of comparisons were performed in this study. In the first set of analyses, mean biochemical parameters after 12 weeks of intervention were compared between

Table 1. Baseline characteristics of participants in the intervention and control groups

\begin{tabular}{lcc}
\hline \multicolumn{1}{c}{ Variables } & $\begin{array}{c}\text { Control group } \\
(\mathrm{n}=30)\end{array}$ & $\begin{array}{c}\text { Intervention } \\
\text { group }(\mathrm{n}=30)\end{array}$ \\
\hline Gender (female/male) & $26 / 4$ & $21 / 9$ \\
Age (years) & $52.23 \pm 8.79$ & $55.33 \pm 9.64$ \\
BMI $\left(\mathrm{kg} / \mathrm{m}^{2}\right)$ & $28.26 \pm 3.65$ & $29.95 \pm 3.48$ \\
HbA1c $(\mathrm{mmol} / \mathrm{mol})$ & $7.23 \pm 0.79$ & $7.20 \pm 0.93$ \\
TG $(\mathrm{mg} / \mathrm{dL})$ & $138.83 \pm 68.24$ & $175.50 \pm 67.56$ \\
FBS $(\mathrm{mg} / \mathrm{dL})$ & $149.80 \pm 43.89$ & $150.83 \pm 47.76$ \\
CHO $(\mathrm{mg} / \mathrm{dL})$ & $170.66 \pm 35.34$ & $178.53 \pm 31.55$ \\
HDL-c $(\mathrm{mg} / \mathrm{dL})$ & $60.83 \pm 17.83$ & $51.13 \pm 14.22$ \\
LDL-c $(\mathrm{mg} / \mathrm{dL})$ & $89.33 \pm 34.09$ & $98.60 \pm 26.26$ \\
\hline
\end{tabular}

Values represent the mean \pm standard deviation.

$\mathrm{BMI}$, body mass index; $\mathrm{HbA1c}$, hemoglobin $\mathrm{A} 1 \mathrm{c}$; $\mathrm{TG}$, triglyceride; FBS, fasting blood sugar; $\mathrm{CHO}$, total cholesterol; HDL-c, high density lipoprotein cholesterol; LDL-c, low density lipoprotein cholesterol. the two groups. In the second set of analyses, in order to adjust for biochemical parameters at the beginning of the study, mean changes before and after the intervention were calculated and compared within each group, with negative values indicating decreases in parameters after the intervention.

No significant difference was observed between the two groups for all parameters except FBS (Table 2). Mean FBS levels after intervention was $159.50 \pm 57.13$ in the control group and $123.73 \pm 33.20$ in the intervention group, indicating FBS levels decreased significantly after consumption of wholegrain wheat bread $(P=0.007)$.

Comparing the mean changes of each parameter from baseline to after the indicated that all parameters except total cholesterol $(P=0.420)$ and LDL-c $(P=0.619)$ significantly changed over the 12-week intervention period. Indeed, after the intervention period, in FBS levels significantly increased by -9.70 units in the control group and 27.10 units in the intervention group $(P=0.002)$ (Table 2).

\section{DISCUSSION}

Diabetes is one of the most common glandular diseases in the world and is responsible for about four million deaths per year (Shaw et al., 2010). Dietary and lifestyle modifications have been considered as alternatives to drug therapies. A diet rich in fiber, independent of energy, fat, and other dietary factors, can reduce mortality rates (Rezvani et al., 2011). In recent years, studies have investigated the beneficial effects of wholegrain wheat bread on blood sugar and fat profile of patients with diabetes (Rezvani et al., 2011; Montazerifar et al., 2016). However, the present study aimed to investigate the effect of wholegrain wheat bread consumption on various physical and biochemical variables, including weight, BMI, FBS, HbAlc, and fat, patients with diabetic.

This study indicated that wholegrain wheat bread could cause significant changes in blood glucose levels in dia-

Table 2. Effect of 12-week wholegrain wheat bread consumption on physical characteristics and biochemical parameters of participants in the intervention and control groups

\begin{tabular}{|c|c|c|c|c|c|c|}
\hline \multirow{2}{*}{ Variables } & \multicolumn{2}{|c|}{ After 12 -week intervention } & \multirow{2}{*}{$P$} & \multicolumn{2}{|c|}{ Mean difference (before to after) } & \multirow{2}{*}{$P$} \\
\hline & Control & Intervention & & Control & Intervention & \\
\hline BMI $\left(\mathrm{kg} / \mathrm{m}^{2}\right)$ & $28.23 \pm 3.84$ & $29.46 \pm 3.32$ & 0.192 & $-0.05 \pm 0.13$ & $0.48 \pm 0.90$ & 0.019 \\
\hline $\mathrm{HbA} 1 \mathrm{c}(\mathrm{mmol} / \mathrm{mol})$ & $7.51 \pm 1.69$ & $8.12 \pm 1.14$ & 0.109 & $-0.27 \pm 1.17$ & $-0.91 \pm 0.86$ & 0.019 \\
\hline $\mathrm{TG}(\mathrm{mg} / \mathrm{dL})$ & $178.44 \pm 35.47$ & $177.06 \pm 38.88$ & 0.790 & $-39.63 \pm 72.61$ & $-1.56 \pm 81.81$ & 0.060 \\
\hline $\mathrm{FBS}(\mathrm{mg} / \mathrm{dL})$ & $159.50 \pm 57.13$ & $123.73 \pm 33.20$ & 0.007 & $-9.70 \pm 43.65$ & $27.1 \pm 43.78$ & 0.002 \\
\hline $\mathrm{CHO}(\mathrm{mg} / \mathrm{dL})$ & $172.03 \pm 35.47$ & $172.06 \pm 38.88$ & 0.790 & $-1.36 \pm 43.47$ & $6.46 \pm 30.35$ & 0.420 \\
\hline $\mathrm{HDL}-\mathrm{c}(\mathrm{mg} / \mathrm{dL})$ & $56.36 \pm 12.57$ & $61.20 \pm 15.21$ & 0.180 & $4.46 \pm 18.30$ & $-10.06 \pm 15.39$ & 0.001 \\
\hline LDL-c (mg/dL) & $102.53 \pm 33.20$ & $91.43 \pm 37.94$ & 0.230 & $32.96 \pm 38.05$ & $37.40 \pm 30.18$ & 0.619 \\
\hline
\end{tabular}

Values represent the mean \pm standard deviation.

Please see Table 1 for the caption and legends. 
betics, which is consistent with results from previous studies (Shidfar et al., 2001; Rezvani et al., 2011). Furthermore, since the amount of glycosylated hemoglobin in diabetics was controlled, it can be concluded that use of wholegrain wheat bread can control blood sugar levels. Other studies have shown that consuming $14 \mathrm{~g}$ of fiber for 6 weeks has no effect on fasting blood sugar levels, but increasing fiber to $23 \mathrm{~g}$ for 4 weeks or $30 \mathrm{~g}$ for 6 weeks reduces fasting blood sugar levels (Manhire et al., 1981; Hollenbeck et al., 1986). It can be concluded that the effect of fiber on blood sugar can be dose-dependent, with lower bran intakes associated with lower glucose absorption, which gradually increases blood sugar levels after meals and prevents prolonged hyperglycemia. In the long-term, higher percentages of bran result in lower glycemic indexes, which increases glucose tolerance and prevents hyperglycemic and insulin resistance. Considering the improvement of patients' glucose tolerance at the end of this study, it can be concluded that increasing bran reduces insulin resistance reduces in patients with T2D and, possibility, decreases incidence of late complications such as retinopathy, nephropathy, neuropathy, and cardiovascular diseases (Cummings et al., 1979; Salmerón et al., 1997; Meyer et al., 2000).

The results of this study indicate that consumption of wholegrain wheat bread significantly reduce triglyceride levels in the intervention group, which is in accordance with studies of Esmaillzadeh et al. (2004) and Jamshidi and Nasrollah Zadeh (2015). Levels of total cholesterol and LDL-c in the intervention group were significantly reduced and the level of HDL-c was increased, which agrees with results from previous studies. Further studies have shown that wholegrain wheat bread can lower total cholesterol and LDL-c levels (Liu et al., 1999; Shidfar et al., 2001). However, other studies have not shown a positive effect of wheat-grain on blood cholesterol (Marsono et al., 1993; Lovegrove et al., 2000). There are discrepancies between the effects of grain on total cholesterol and LDL-c due to the amount of grain consumption, its duration and knowledge of the control of factors affecting blood lipids such as diet.

The positive effect of wholegrain wheat bread is due to its direct effects on fecal secretion of bile acids, which increases conodoxycholic acid, inhibiting $\beta$-hydroxy $\beta$ methylglutaryl-coenzyme A to inhibit production of hepatic cholesterol. Bacterial fermentation of fiber in the colon also produces short-chain fatty acids including propionic acid, which causes synthesis of hepatic cholesterol. This can reduce digestion and absorption of fats in foods, including cholesterol, and increase excretion of bile acids through the intestine, which promotes conversion of cholesterol in liver cells to be converted into bile acids to replace excreted bile acids. Therefore, the need of liver cells for cholesterol increases. As a result, these cells increase expression of LDL-c and more LDL particles are removed from the blood by receptors, thereby entering blood cells where they are broken down and the existing cholesterol is used to produce bile acids. This reduces the concentration of LDL-c and total cholesterol in the blood (Truswell, 1995).

In general, this study showed that consuming $180 \mathrm{~g} / \mathrm{d}$ wholegrain wheat bread for 3 months can control blood sugar levels, and reduce glycosylated hemoglobin, glycosylated hemoglobin, triglycerides, total cholesterol, and LDL-c, and increase HDL-c levels. These changes can play an effective role in the treatment of hypercholesterolemia and the prevention of cardiovascular diseases in these patients.

This study indicated that consumption of wholegrain wheat bread has positive effects on improving the physicochemical parameters of patients with diabetes and the general public. However, further culture building and public education is important about the need to include wholegrain wheat bread in daily diets. Healthcare workers, such as nutritionists, health experts, healthcare providers, and health workers, can play an undeniable role in promoting awareness, attitude, and practice of people in their consumption of wholegrain wheat bread and wheat grains. Health networks in Iran are located throughout the country in urban and rural areas, and health forces have established good internal and external co-operations with various organizations and NGOs (both private and public) in their covered regions (Moradzadeh et al., 2020; Nazari et al., 2020). By studying future nutritional trends and health problems (Dehnavieh et al., 2019), the Ministry of Health should provide a comprehensive program to improve the quality of nutrition and education (Marzbani et al., 2019) and provide advocacy guidelines for the involvement of relevant organizations, including ministries of industry and mine and trade, governorships, provincial governments, sheriffdoms, bakers' unions, and other stakeholders to promote healthy lifestyles that include consumption of wholegrain wheat breads.

Diabetes is a major health problem that causes high morbidity and mortality without definitive treatment. Drugs to control diabetes have many limitations, side effects, and significant costs. However, according to the results of this study, consumption of wholegrain wheat breads should be on the agenda of educational programs of health centers across the country due to their positive effects on controlling various physical and biochemical indicators of patients with T2D. In these educational programs, in addition to identifying and introducing breads containing wholegrain and the amounts of wholegrains in each bread, special nutritional programs should be provided for different groups of people with diabetes. It is known that diets rich in fiber, independent of energy, fat, and other dietary factors, can reduce health problems. 
Therefore, it is necessary for healthcare system to hold external meetings with various city departments and organizations, including the ministries of industry and mine and trade, governorships, provincial governments, sheriffdoms, bakers' unions, and other stakeholders, in order to determine the percentages of bran in flour of different bakeries. These percentages should be communicated to the public, and these organizations should supervise its proper implementation and the introduction of violators to regulatory bodies.

\section{AUTHOR DISCLOSURE STATEMENT}

The authors declare no conflict of interest.

\section{REFERENCES}

American Diabetes Association. Diagnosis and classification of diabetes mellitus. Diabetes Care. 2009. 32:S62-S67.

Beisswenger P, Heine RJ, Leiter LA, Moses A, Tuomilehto J. Prandial glucose regulation in the glucose triad: emerging evidence and insights. Endocrine. 2004. 25:195-202.

Bosello O, Ostuzzi R, Armellini F, Micciolo R, Scuro LA. Glucose tolerance and blood lipids in bran-fed patients with impaired glucose tolerance. Diabetes Care. 1980. 3:46-49.

Brodribb AJ, Humphreys DM. Diverticular disease: three studies. Part III-Metabolic effect of bran in patients with diverticular disease. Br Med J. 1976. 1:428-430.

Cummings JH, Southgate DA, Branch WJ, Wiggins HS, Houston $\mathrm{H}$, Jenkins DJ, et al. The digestion of pectin in the human gut and its effect on calcium absorption and large bowel function. Br J Nutr. 1979. 41:477-485.

Dehnavieh R, Khosravi S, Mehrolhassani MH, Haghdoost A, Amini S. Future trends of the primary healthcare system in Iran: a qualitative study. Int J Prev Med. 2019. 10:158. https://doi. org/10.4103/ijpvm.IJPVM_334_18

Esmaillzadeh A, Mirmiran P, Mirhosseini M, Azizi F. The relationship between whole-grain consumption, the metabolic syndrome and cardiovascular risk factors in Tehran adults population. J Diabetes Metab Disord. 2004. 3:113-126.

Esposito K, Maiorino MI, Di Palo C, Giugliano D; Campanian Post-Prandial Hyperglycemia Study Group. Dietary glycemic index and glycemic load are associated with metabolic control in type 2 diabetes: The CAPRI experience. Metab Syndr Relat Disord. 2010. 8:255-261.

Global Burden of Disease Study 2019. Results (database on the Internet). 2020 [2021 Jul 3]. Available from: http://ghdx. healthdata.org/gbdresults-tool

Gray A, Threlkeld RJ. Nutritional recommendations for individuals with diabetes. MDText.com, Inc., Dartmouth, MA, USA. 2015 [cited 2021 Jul 10]. Available from: https://www.ncbi. nlm.nih.gov/books/NBK279012/

Guariguata L. By the numbers: new estimates from the IDF Diabetes Atlas Update for 2012. Diabetes Res Clin Pract. 2012. 98: 524-525.

Hollenbeck CB, Coulston AM, Reaven GM. To what extent does increased dietary fiber improve glucose and lipid metabolism in patients with noninsulin-dependent diabetes mellitus (NIDDM)?. Am J Clin Nutr. 1986. 43:16-24.

Jamshidi A, Nasrollah Zadeh A. The effect of rice bran and wheat bran on the level of blood sugar and cholesterol in people with type 2 diabetes. The first national conference on inclusive strategic quality development in food health. 2015 [cited 2021 Jul 18]. Available at: https://www.civilica.com/Paper-IRANQMS01IRANQMS01_195.html

Javanbakht M, Baradaran HR, Mashayekhi A, Haghdoost AA, Khamseh ME, Kharazmi E, et al. Cost-of-illness analysis of type 2 diabetes mellitus in Iran. PLoS One. 2011. 6:e26864.

Jenkins A, Vuksan V, Kacinik V, Lyon M. Glycemic index reduction by a viscous polysaccharide blend independent of food form: determination of the glycemic reduction index potential (GRIP). FASEB J. 2008a. 22:305.7-305.7.

Jenkins AL, Kacinik V, Lyon M, Wolever TM. Effect of adding the novel fiber, $\mathrm{PGX}{ }^{\mathbb{R}}$, to commonly consumed foods on glycemic response, glycemic index and GRIP: a simple and effective strategy for reducing post prandial blood glucose levels - a randomized, controlled trial. Nutr J. 2010. 9:58. https://doi.org/ 10.1186/1475-2891-9-58

Jenkins DJ, Kendall CW, McKeown-Eyssen G, Josse RG, Silverberg J, Booth GL, et al. Effect of a low-glycemic index or a high-cereal fiber diet on type 2 diabetes: a randomized trial. JAMA. 2008b. 300:2742-2753.

Liu S, Stampfer MJ, Hu FB, Giovannucci E, Rimm E, Manson JE, et al. Whole-grain consumption and risk of coronary heart disease: results from the Nurses' Health Study. Am J Clin Nutr. 1999. 70:412-419.

Livesey G, Taylor R, Hulshof T, Howlett J. Glycemic response and health - a systematic review and meta-analysis: relations between dietary glycemic properties and health outcomes. Am J Clin Nutr. 2008. 87:258S-268S.

Lovegrove JA, Clohessy A, Milon H, Williams CM. Modest doses of $\beta$-glucan do not reduce concentrations of potentially atherogenic lipoproteins. Am J Clin Nutr. 2000. 72:49-55.

Ma CY, Harwalkar VR. Chemical characterization and functionality assessment of oat protein fractions. J Agric Food Chem. 1984. 32:144-149.

Manhire A, Henry CL, Hartog M, Heaton KW. Unrefined carbohydrate and dietary fibre in treatment of diabetes mellitus. J Hum Nutr. 1981. 35:99-101.

Marsono Y, Illman RJ, Clarke JM, Trimble RP, Topping DL. Plasma lipids and large bowel volatile fatty acids in pigs fed on white rice, brown rice and rice bran. Br J Nutr. 1993. 70:503513.

Marzbani B, Nazari J, Najafi F, Marzbani B, Shahabadi S, Amini M, et al. Dietary patterns, nutrition, and risk of breast cancer: a case-control study in the west of Iran. Epidemiol Health. 2019. 41:e2019003. https://doi.org/10.4178/epih.e2019003

Meyer KA, Kushi LH, Jacobs DR Jr, Slavin J, Sellers TA, Folsom AR. Carbohydrates, dietary fiber, and incident type 2 diabetes in older women. Am J Clin Nutr. 2000. 71:921-930.

Montazerifar F, Karajibani M, Keikhaie MAA, Dashipoor AR, Amian M, Nekuie E. The effect of consumed breads on glycemic response of patients with type 2 diabetes. Yafte. 2016. 18: 67-75.

Moradzadeh R, Nazari J, Shamsi M, Amini S. Knowledge, attitudes, and practices toward coronavirus disease 2019 in the central area of Iran: a population-based study. Front Public Health. 2020. 8:599007. https://doi.org/10.3389/fpubh.2020. 599007

Nazari J, Amini S, Amiresmaili M. Lessons learned to control COVID-19 to prevent a crisis: the case of Iran. Open Public Health J. 2020. 13:529-530.

Rezvani V, Najjar Safari SH, Hajifaraji M, Rashidkhani B. The effect of "real oat bread" compared with "barley bread offered in Tehran" on serum glucose and lipid profiles in dislipidemic and type 2 diabetic subjects. Iranian J Endocrinol Metab. 2011. 13: 233-242.

Roberts CK, Liu S. Effects of glycemic load on metabolic health 
and type 2 diabetes mellitus. J Diabetes Sci Technol. 2009. 3:697-704.

Salmerón J, Manson JE, Stampfer MJ, Colditz GA, Wing AL, Willett WC. Dietary fiber, glycemic load, and risk of non-insulin-dependent diabetes mellitus in women. JAMA. 1997. 277:472477.

Shaw JE, Sicree RA, Zimmet PZ. Global estimates of the prevalence of diabetes for 2010 and 2030. Diabetes Res Clin Pract. 2010. 87:4-14.

Shidfar F, Keshavarz A, Avaspour M. The effect of two types of bread with different fiber contents on biochemical parameters of patients with type II diabetes. Iranian J Endocrinol Metab. 2001. 3:257-264.

Shishehbor F, Shamekhi Z, Karandish M, Latifi SM. Correlation between quality and quantity of dietary carbohydrate and obesity in a group of women from Ahvaz. J Fasa Univ Med Sci. 2013. 3:230-234.
Truswell AS. Dietary fibre and blood lipids. Curr Opin Lipidol. 1995. 6:14-19.

Veisani Y, Khazaei S, Jenabi E, Delpisheh A. Diabetes mortality and morbidity trends and related risk factors in Iranian adults: an appraisal via current data. J Tehran Heart Cent. 2018. 13: 195-197.

Webster FH, Wood PJ. OATS: chemistry and technology. American Association of Cereal Chemists, St. Paul, MN, USA. 1986. p 430.

Whiting DR, Guariguata L, Weil C, Shaw J. IDF diabetes atlas: global estimates of the prevalence of diabetes for 2011 and 2030. Diabetes Res Clin Pract. 2011. 94:311-321.

WHO/IDF. Definition and diagnosis of diabetes mellitus and intermediate hyperglycaemia: report of a WHO/IDF consultation. 2006 [cited 2021 Jul 3]. Available from: https://apps. who.int/iris/handle/10665/43588 